\title{
Investigation of Post Vaccination Reactions of Two Live Attenuated Vaccines against Lumpy Skin Disease of Cattle
}

\author{
Zahra Bamouh ${ }^{1,2, *} \mathbb{0}$, Jihane Hamdi ${ }^{1,2}$, Siham Fellahi ${ }^{2} \mathbb{D}$, Slimane Khayi ${ }^{3}{ }^{\mathbb{D}}$, Mohammed Jazouli $^{1}$, \\ Khalid Omari Tadlaoui ${ }^{1}$, Ouafaa Fassi Fihri ${ }^{2}$, Eeva Tuppurainen ${ }^{4}$ and Mehdi Elharrak ${ }^{1}$ \\ 1 MCI Santé Animale, Mohammedia 28810, Morocco; jihaneh.hamdi@gmail.com (J.H.); \\ jazouli_med@yahoo.fr(M.J.); k.tadlaoui@mci-santeanimale.com (K.O.T.); \\ m.elharrak@mci-santeanimale.com (M.E.) \\ 2 Institut Agronomique et Vétérinaire Hassan II, B.P 6202, Rabat 10112, Morocco; s.fellahi@iav.ac.ma (S.F.); \\ o.fassifihri@iav.ac.ma (O.F.F.) \\ 3 CRRA-Rabat, National Institute for Agricultural Research (INRA), Rabat 10101, Morocco; \\ slimane.khayi@inra.ma \\ 4 Institut für Internationale Tiergesundheit/One Health, Friedrich-Loeffler-Institut Federal Research Institute \\ for Animal Health, 1017493 Greifswald-Insel Riems, Germany; eeva.tuppurainen@fli.de \\ * Correspondence: z.bamouh@mci-santeanimale.com; Tel.: +212-6621-989-42
}

\section{check for} updates

Citation: Bamouh, Z.; Hamdi, J.; Fellahi, S.; Khayi, S.; Jazouli, M.; Tadlaoui, K.O.; Fihri, O.F.; Tuppurainen, E.; Elharrak, M. Investigation of Post Vaccination Reactions of Two Live Attenuated Vaccines against Lumpy Skin Disease of Cattle. Vaccines 2021, 9, 621. https://doi.org/10.3390/vaccines906 0621

Academic Editor: Shawn Babiuk

Received: 31 March 2021

Accepted: 5 May 2021

Published: 8 June 2021

Publisher's Note: MDPI stays neutral with regard to jurisdictional claims in published maps and institutional affiliations.

Copyright: (c) 2021 by the authors. Licensee MDPI, Basel, Switzerland. This article is an open access article distributed under the terms and conditions of the Creative Commons Attribution (CC BY) license (https:/ / creativecommons.org/licenses/by/ $4.0 /)$.

\begin{abstract}
Lumpy skin disease virus (LSDV) causes an economically important disease in cattle. The only method for successful control is early diagnosis and efficient vaccination. Adverse effects of vaccination such as local inflammation at the injection site and localized or generalized skin lesions in some vaccinated animals have been reported with live vaccines. The aim of this work was to compare the safety of two lumpy skin disease (LSD) vaccine strains, Kenyan (Kn) Sheep and Goat Pox (KSGP O-240) and LSDV Neethling (Nt) strain, and to determine the etiology of the post-vaccination (pv) reactions observed in cattle. Experimental cattle were vaccinated under controlled conditions with Nt- and KSGP O-240-based vaccines, using two different doses, and animals were observed for 3 months for any adverse reactions. Three out of 45 cattle vaccinated with LSDV Nt strain $(6.7 \%)$ and three out of 24 cattle vaccinated with Kn strain (12.5\%) presented LSD-like skin nodules, providing evidence that the post-vaccination lesions may not be strain-dependent. Lesions appeared 1-3 weeks after vaccination and were localized in the neck or covering the whole body. Animals recovered after 3 weeks. There is a positive correlation between the vaccine dose and the appearance of skin lesions in vaccinated animals; at the 105 dose, $12 \%$ of the animals reacted versus $3.7 \%$ at the 104 dose. Both strains induced solid immunity when protection was measured by neutralizing antibody seroconversion.
\end{abstract}

Keywords: lumpy skin disease virus; safety; Neethling disease; vaccination; cattle

\section{Introduction}

Lumpy skin disease (LSD) is an economically devastating infectious disease of cattle occurring in Africa, the Middle East, southeastern Europe, northern Caucasus, the Russian Federation, the Indian subcontinent, and south, east, and southeast Asia with a high economic importance [1]. Lumpy skin disease is caused by the LSD virus (LSDV), belonging to the Poxviridae family, genus Capripoxvirus [2]. Transmission is due to arthropod vectors, including biting flies, mosquitoes, and hard ticks [3,4]. Although direct transmission is not considered a major route of transmission during epizootics, it may occur by contact through contaminated saliva, semen, milk, or skin lesions [4-9]. Lumpy skin disease infections in cattle range from inapparent to severe manifestations, producing clinical symptoms such as fever associated with a marked reduction in milk yield, ocular and nasal discharge, hypersalivation, and enlarged lymph nodes. Lumpy skin disease is characterized by cutaneous nodules of $2-5 \mathrm{~cm}$ in diameter across different body locations that evolve into 
large nodules that may become necrotic. Ulcers can be detected in the digestive and respiratory tracts, and pregnant cows may abort [10-14].

The most effective way to control LSD in endemic countries is to carry out large-scale vaccinations with safe and effective vaccines. All three members of the Capripox genus have been used to immunize cattle against LSD. The homologous South African Neethling (Nt) strain has been used worldwide, while Kenyan $(\mathrm{Kn})$ strain use is limited to a few countries: Israel [15], Ethiopia [16], and Egypt [17]. Heterologous strains based on sheep pox (RM65 and Romania strains) or goat pox (Gorgan strain) are also used to prevent LSD, but the efficacy of the different vaccine products varies $[16,18,19]$. Lumpy skin disease virus-based vaccines may induce adverse reactions such as fever and lymphadenitis. Neethling disease was reported by Yerhun et al. with Nt vaccines [15] and by Abutarbush et al. with 10 sheep doses of RM65 vaccine [20]. The percentage of vaccinated animals showing LSD-like nodules after vaccination ranges from $0.38 \%$ to $12 \%$ according to field observations [21,22]. According to Israeli experience, the LSD Nt vaccine caused only mild adverse effects at a very low incidence $(0.38-0.6 \%$ ) [21]. In Croatia, adverse reactions were reported in $0.09 \%$ of the vaccinated animals using a homologous vaccine [23]. In a study carried out by Greek scientists, a local reaction at the vaccination site was detected in $12 \%$ and generalized small-sized lumps in $9 \%$ of animals vaccinated with a commercially available LSD Nt strain vaccine [22]. LSD-like lesions, following vaccination, were reported by researchers in Jordan in $8 \%$ of cattle vaccinated with RM-65 vaccine strain [24]. The differences in reported percentages of LSD-like nodules post vaccination are probably associated with differences in pre-existing immunity such as previous vaccinations or with the reluctance of farmers to report the side-effects in their vaccinated herds. The cause for the appearance of the post-vaccination skin nodules may vary across vaccine strains, vaccine dosage used, immune status of the vaccinated animal, or recurrent infections of the animals.

To investigate the side-effects caused by two different attenuated homologous LSDV strains (Nt and Kn KSGP-O 240), four groups of cattle were vaccinated in a controlled environment, using two different doses. The vaccinated experimental animals were closely monitored for appearance of the side-effects, and seroconversion was evaluated for 3 months post vaccination.

\section{Materials and Methods}

\subsection{Vaccine Preparation}

The attenuated Nt LSD strain, commonly used in vaccine preparation, was provided by the Pirbright Institute. The passage number of this strain is not known. To prepare the vaccine, the strain was once propagated in ovine primary testis cells in our laboratory and then harvested. A stabilizer (4\% peptone, $8 \%$ sucrose, and $2 \%$ glutamate) was added to the virus suspension, which was then freeze-dried. The vaccine was tested for bacterial sterility, strain identity, purity, and infectious titer. Experimental animals were vaccinated with a volume of $2 \mathrm{~mL}$ of $10^{4.0} \mathrm{TCID}_{50}$ (low dose) or $2 \mathrm{~mL}$ of $10^{5.0} \mathrm{TCID}_{50}$ (high dose).

The LSD Kn (KSGP O-240) strain was also provided by the Pirbright Institute and used to prepare the other live attenuated vaccine of this study. The strain was passed three times in primary lamb testis cells and presented a titer of $10^{5.0} \mathrm{TCID}_{50} / \mathrm{mL}$; the vaccine was then injected subcutaneously ito five naïve cattle ( $5 \mathrm{~mL}$ each). Any animal presenting skin lesions post vaccination was submitted to viral isolation and PCR. Re-isolation was performed in ovine primary testis cells by inoculation of the homogenate of the skin inflammation tissue. The harvested virus was tested for identity and purity and used to prepare the vaccine as described above for the $\mathrm{Nt}$ strain. Experimental animals were vaccinated using a volume of $2 \mathrm{~mL}$ of $10^{4.0} \mathrm{TCID}_{50}$ (low dose) and $10^{5.0} \mathrm{TCID}_{50}$ (high dose).

LSD Nt and Kn vaccines were reconstituted with a sterile phosphate saline diluent. Directly after the reconstitution, the vaccines were inoculated subcutaneously into the neck region of the experimental cattle. 


\subsection{Sequencing}

The whole-genome sequencing of the LSD Nt strain was performed by Sciensano, Belgium to confirm the identity of the strain. The LSDV Kn strain DNA was obtained from a skin sample collected from a calf used to refresh the strain. The DNA was extracted using an Isolate II Genomic DNA kit (Qiagen, Germany) according to the manufacturer's instructions. The whole-genome sequencing was carried out by the Eurofins Genomics company using Genome Sequencer Illumina HiSeq (Constance, Germany) and sequence mode NovaSeq 6000 S2 PE150 XP platforms. The raw reads were trimmed using CLC genomics workbench v12 (Qiagen) (limit $=0.05$, ambiguous nucleotides $n \leq 2$ ). The trimmed reads were de novo assembled using CLC genomics workbench v12.

Full-length GPCR and RPO30 genes were retrieved from the assembly. The resulting sequences were aligned together with the reference sequences retrieved from GenBank for each gene using the CLUSTALW algorithm [25] in BioEdit 7.2.5 [26]. Molecular phylogenetic analyses were performed using MEGA 10.2.2 [27]. The evolutionary history was inferred using the neighbor-joining method [28], and confidence on branching was assessed using bootstrap resampling (1000 replicates) [29]. The evolutionary distances were computed using the Kimura two-parameter method [30].

The purpose of the sequencing was to confirm identity with the reference strain (ID: KX683219) reported by Vandenbussche et al. 2016 [31] and analyze variants of the obtained sequence (indels and single-nucleotide polymorphisms (SNPs)) [31].

\subsection{Experimental Animals}

The study protocol was approved by the Internal Laboratory Ethic Committee of MCI Santé Animale (Protocol number RD1V1730). In addition, the international guidelines for caring and handling of experimental animals as described in Chapter 7.8 of the Terrestrial Animal Health Code and Directive 2010/63/UE of the European Commission [32,33] were followed.

Seventy-three Holstein-cross breed, healthy calves, 4 to 6 months of age, were purchased from a selected cattle breeding farm. Currently, Morocco is free of LSD, and the experimental cattle were housed in fly-proof pens at cattle quarantine facilities located in the northwest region of Morocco. Prior to the onset of the experiment, the animals were allowed to acclimatize for 15 days and were monitored daily for fever and appearance of any nonspecific clinical signs. Blood samples were collected prior to vaccination to confirm the absence of anti-LSD antibodies using the virus neutralization test (VNT). Cattle were fed a complete balanced diet and water ad libitum during acclimatization and experimental periods. Cattle were randomly selected and were divided into five homogenous groups: G1: (15 animals) vaccinated with $2 \mathrm{~mL}$ of $10^{4} \mathrm{TCID}_{50} / \mathrm{mL}$, the low dose of $\mathrm{Nt}$ vaccine, G2: (30 animals) vaccinated with $10^{5} \mathrm{TCID}_{50} / \mathrm{mL}$, the high dose of Nt vaccine, G3: (12 animals) vaccinated with $10^{4} \mathrm{TCID}_{50} / \mathrm{mL}$, the low dose of Kn vaccine, G4: (12 animals) vaccinated with $10^{5} \mathrm{TCID}_{50} / \mathrm{mL}$, the high dose of $\mathrm{Kn}$ vaccine, and G5: (four animals) unvaccinated control animals inoculated with a placebo solution. Cattle were housed in separate boxes at a level 3 biosecurity containment and injected subcutaneously on the right side of the neck with $2 \mathrm{~mL}$ of the appropriate vaccine and observed for 90 days post vaccination (pv). The body temperature was recorded daily for 14 days, and general body condition was evaluated and scored for each animal. Clinical scoring for each parameter ranged from 0-2 or $0-5$ as outlined in Table 1 . To preserve the trial objectivity, animal carers or investigators were blinded to the vaccine type and dose. Roles and responsibilities were prespecified. Clinical signs were scored as described in Table 1; a total cumulative score of assessed signs per animal and group per day was calculated. Blood samples were collected from each animal by jugular venipuncture on day (D) 0 (before vaccination), D7, D14, D21, D28, D35, D42 D60, and D90 pv. Sera were stored at $-20^{\circ} \mathrm{C}$ until analysis. At the end of the experiment, cattle were euthanized using humane slaughter. 
Table 1. Scoring of recorded clinical signs.

\begin{tabular}{ccc}
\hline & Clinical Signs & Score \\
\hline \multirow{3}{*}{ General behavior } & Normal & 0 \\
& Inactive & 1 \\
& Very inactive & 2 \\
\hline \multirow{2}{*}{ Fever } & Normal & 0 \\
& $39-40^{\circ} \mathrm{C}$ & 1 \\
Food uptake & $>40^{\circ} \mathrm{C}$ & 2 \\
\hline \multirow{3}{*}{ Local inflammation } & Normal & 0 \\
& Loss of appetite & 1 \\
& Anorexia & 2 \\
\hline \multirow{3}{*}{ Neethling Disease } & None & 0 \\
& $<2 \mathrm{~cm}$ & 1 \\
& $>2 \mathrm{~cm}$ & 2 \\
\hline & None & 0 \\
& $>5$ nodules in three areas & 1 \\
& Generalized nodules & 2 \\
& & 3
\end{tabular}

\subsection{Virus Neutralization (VNT)}

The humoral response of animals to LSD vaccination was evaluated by testing serum samples using the VNT method as described in the OIE current version of the Terrestrial Manual (OIE Chapters 2.7.12). Sera were heat-inactivated, and serial 1:3 dilutions were mixed with a constant dose of LSD virus followed by incubation for $1 \mathrm{~h}$. A Madin-Darby Bovine Kidney (ATCC ${ }^{\circledR}$ CCL-22 ${ }^{\mathrm{TM}}$, Manassas, VA, USA) cell suspension was then added, inoculated on cells, and observed after 7 days for the presence of cytopathic effect (CPE). To validate the used viral dose, dilutions without sera were inoculated on cells and observed for 7 days for the presence of CPE. The neutralizing antibody titer was calculated according to the method used by Reed and Muench (1937).

\section{5. $P C R$}

Nasal and oral swabs were collected from vaccinated cattle on days $3,6,9,12,21$, 28 , and $35 \mathrm{pv}$ to detect LSDV excretion using quantitative real-time PCR (qPCR). All samples were transferred to the laboratory on ice. Swabs were collected in $2 \mathrm{~mL}$ of phosphate-buffered saline (PBS) and then centrifuged at $2000 \mathrm{rpm}$ for $20 \mathrm{~min}$ at $4{ }^{\circ} \mathrm{C}$ degrees. Viral DNA was extracted using ISOLATE II Genomic DNA Kit (Bioline, London, UK). Samples were tested by a qPCR TaqMan assay that detects the $89 \mathrm{bp}$ region from ORF074 encoding the intracellular mature virion envelope protein P32 within SPPV, GTPV, and LSDV. Real-time PCR was conducted with a Luna Universal Probe QPCR Master Mix Kit (New England Biolabs, Ipswich, USA). The reaction was performed in 96-well optical reaction plates, containing $12.5 \mu \mathrm{L}$ of $2 \times$ Universal Probe QPCR Master Mix, $1 \mu \mathrm{L}$ of each primer cited by Bowden [6], $5 \mu \mathrm{L}$ of template (DNA), and $5 \mu \mathrm{L}$ of nuclease-free water. The qPCR assay was run and optimized in ABI7500 (Applied Biosystems, Foster City, California, USA) with the following cycling conditions: $95^{\circ} \mathrm{C}$ for $10 \mathrm{~min}$, followed by 45 cycles of PCR at $95^{\circ} \mathrm{C}$ for $15 \mathrm{~s}$ and $60^{\circ} \mathrm{C}$ for $1 \mathrm{~min}$.

Virus recovery from cutaneous lesions: The LSD virus was reisolated from the skin sample collected from the only animal that showed local inflammation of 3 to $5 \mathrm{~cm}$ of diameter at the injection site. Identity of the agent was confirmed by the development of typical CPE followed by cell lysis at 5 days post infection and through PCR confirmation.

Statistical analyses were performed using Student $t$-test models. Comparisons were carried out between vaccinated groups on the basis of clinical scoring and Neethling-like disease presence. Values of $p \leq 0.05$ were considered significant. 
GenBank accession numbers. The full genome sequences of LSD Kn KSGP O-240 strain after refreshment on cattle were analyzed in this study and deposited in GenBank (accession number MW631933).

The sequences of RPO30 and GPCR genes of LSD Kn strain under study were compared with the sequences of LSD already available on the public sequence databases of the GenBank under the following accession numbers for the RPO30 gene: KJ818288; MT448696; MT448695; MT448694; MT448693; MT448692; MT448691; MN967006; MT228884; MT228883; MT228882; MT228881; MG201832; MK302094; GU119944; KJ818290; KJ818289; KJ818288; MN518933; MN598007; GU119938; GU119943; GU119945; GU119946; GU119947; GU119948; GU119951; GU119952; GU119950; GU119937; KX683219.

Comparisons were also made using the following accession numbers for the GPCR gene: FJ869367; FJ869372; FJ869368; MT448700; FJ869352; FJ869369; FJ869370; FJ869373; FJ869371; KP663706; FJ869377; MT448701; FJ869374; FJ869375; MK452255; FJ869366; MT448699; MT448697; MT448698; FJ818283; FJ818282; FJ818281; KX683219; MN508357; MK358808; FJ869376; MN598006; FJ869365; MF156212; MG970343.

\section{Results}

Virus isolation: Both Nt and Kn LSD strains grew on ovine primary testis cells. Strains showed characteristic CPE starting from day 3 and were harvested on day 5 pi. The titration performed on both viruses revealed a titer of $10^{6.9}$ and $10^{7.0} \mathrm{TCID}_{50} / \mathrm{mL}$ for $\mathrm{Nt}$ and $\mathrm{Kn}$ viruses, respectively. Final vaccines complied with analytical QC testing [34].

The LSD Nt strain used in this experiment showed 100\% similarity with sequence data from LSDN stored in the GenBank (ID: AF409138). The whole-genome sequence and assembly of KSGP O-240 strain refreshed on experimental cattle contained 146,090 bps and $26 \% \mathrm{G}+\mathrm{C}$ content. Variant calling, using the reference sequence (KX683219), revealed seven variants: two single-nucleotide deletions, three single-nucleotide substitutions (SNVs), and two single-nucleotide insertions (Table 2).

Table 2. SNPs (single-nucleotide polymorphisms) of KSGP O-240 refreshed on animal.

\begin{tabular}{|c|c|c|c|c|c|c|c|}
\hline $\begin{array}{l}\text { Reference } \\
\text { Position }\end{array}$ & Type & Length & Ref & Allele & $\begin{array}{l}\text { Overlapping } \\
\text { Annotations }\end{array}$ & Coding Region Change & Amino Acid Change \\
\hline 17 & SNV & 1 & $\mathrm{~T}$ & $\mathrm{~A}$ & \multirow{4}{*}{$\begin{array}{l}\text { Gene: LSDV026, } \\
\text { CDS: LSDV026 }\end{array}$} & \multirow{4}{*}{ AOE47602.1:c.479del } & \multirow{4}{*}{ AOE47602.1:p.Leu160fs } \\
\hline 18,578 & Deletion & 1 & A & - & & & \\
\hline 22,772 & Insertion & 1 & - & A & & & \\
\hline 28,073 & Insertion & 1 & - & $\mathrm{T}$ & & & \\
\hline 84,168 & SNV & 1 & $\mathrm{C}$ & A & \multirow{3}{*}{$\begin{array}{l}\text { Gene: LSDV089, } \\
\text { CDS: LSDV089 } \\
\text { Gene: LSDV094, } \\
\text { CDS: LSDV094 }\end{array}$} & \multirow{3}{*}{$\begin{array}{l}\text { AOE47665.1:c. } 48 \mathrm{G}>\mathrm{T} \\
\text { AOE47670.1:c. } 254 \mathrm{C}>\mathrm{A}\end{array}$} & \multirow{3}{*}{$\begin{array}{l}\text { AOE47665.1:p.Leu16Phe } \\
\text { AOE47670.1:p.Pro85His }\end{array}$} \\
\hline 89,076 & SNV & 1 & G & $\mathrm{T}$ & & & \\
\hline 125,083 & Deletion & 1 & A & - & & & \\
\hline
\end{tabular}

Despite those seven noted changes in the KSGP O-240 strain, only three genes were affected with no consequences for strain identity. The Kn strain used shared $99 \%$ homology with the LSD strain (ID: KX683219). According to the complete genome sequence, the strain KSGP O-240 was confirmed to be an LSDV.

The sequences of RPO30 and GPCR genes were determined for the Kn strain before and after refreshment. These were compared with the sequences of LSDV already available on the public sequence databases. Molecular phylogenetic analyses were performed on the coding regions of the RPO30 gene (31 sequences, 606 positions; Figure 1) and the GPCR gene (30 sequences, 1146 positions; Figure 2). These results confirmed the identification made using real-time PCR. 


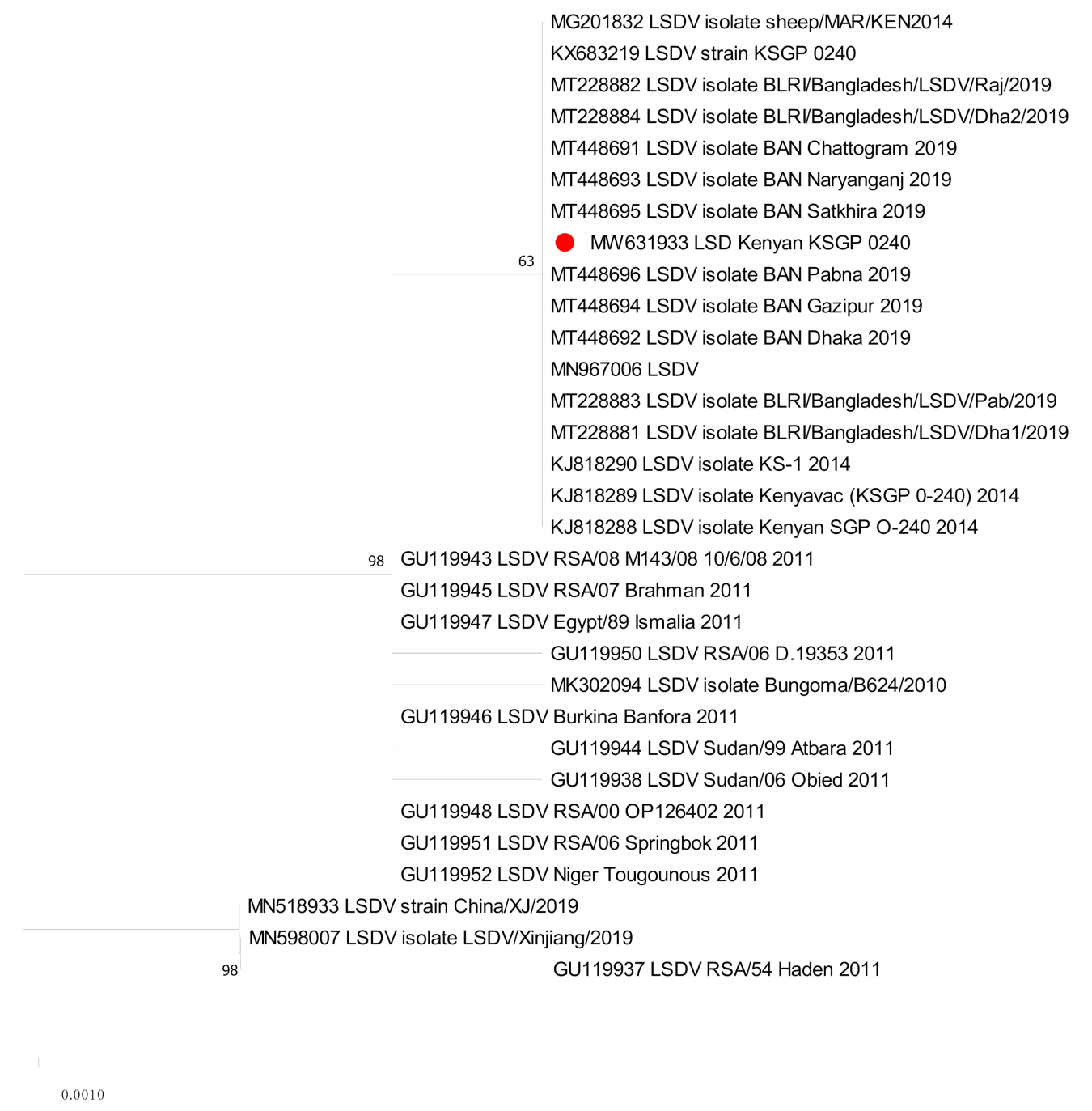

Figure 1. Molecular phylogenetic analysis of the Capripoxvirus RNA polymerase subunit gene (RPO30). The RPO30 sequence obtained in this study was marked with red circle shaped symbols.

The phylogenetic analysis of the RPO30 and GPCR genes, with multiple sequence alignments, revealed that our Kn strain was closely related to LSDV KSGP O-240, LSDV $\mathrm{Kn}$, and Bangladesh LSD isolates.

On the RPO30 tree (Figure 1), the Kn strain in this study clustered with Bangladesh isolates 2019, LSDV KSGP O-240 (KJ818288) known as LSDV KS1, and LSDV KSGP O-240 (KX683219). On the GPCR tree (Figure 2), our strain was closely clustered with LSDV KSGPO-240 (KX683219) and LSDV KSGP-0240 (KJ818281) and (KJ818282).

Body temperature: In Group 1, out of 15 animals, seven presented moderate hyperthermia (maximum temperature recorded was $40{ }^{\circ} \mathrm{C}$ ) for 2 days, starting from D2 (average duration of 0.93 days/animal). In Group 2, 13 animals among 30 developed moderate hyperthermia (maximum temperature recorded is $40.8^{\circ} \mathrm{C}$ ), two animals for 1 day, five animals for 3 days, three animals for 5 days, and three animals for 8 days (1.87 days/animal). In Group 3, five calves among 12 showed hyperthermia (maximum temperature recorded is $41.9^{\circ} \mathrm{C}$ ), two animals for 5 days and three animals for 6 days (2.33 days/animal). In Group 4, nine among 12 animals developed hyperthermia (maximum temperature recorded is $41.1^{\circ} \mathrm{C}$ ), two animals for 1 day, two for 6 days, four for 3 days, and one for 9 days (2.92 days/animal). The body temperature of unvaccinated cattle (G5) remained normal and did not exceed $39^{\circ} \mathrm{C}$ (Figure 3). 


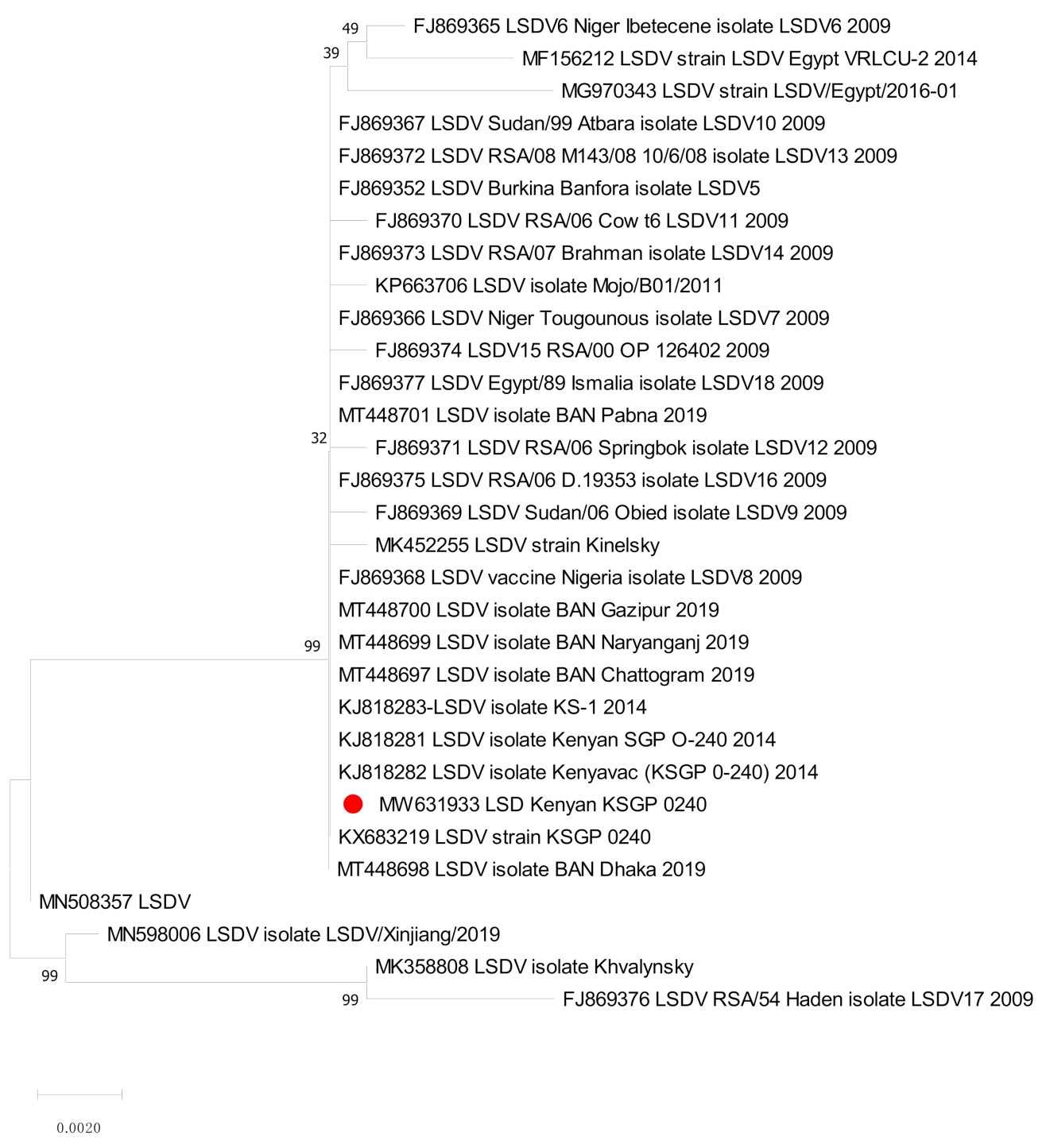

Figure 2. Molecular phylogenetic analysis of KSGP O-240 strain based on the Capripoxvirus G-proteincoupled chemokine receptor (GPCR) gene. The GPCR sequence obtained in this study was marked with red circle shaped symbols.

Clinical scoring: Cattle vaccinated with $\mathrm{Nt}$ or $\mathrm{Kn}$ strains remained healthy; only cattle of G4 presented a clinical scoring of 2.5, due to the appearance of LSD-like lesions. The control group did not show any clinical signs (Table 3). Six out of $69(8.7 \%)$ vaccinated animals showed LSD-like nodules in different parts of the body. In G1, one Neethling disease case was observed, whereas two cases and three cases were observed in G2 and G4, respectively. No cases were noted in G3 (Table 3).

Briefly, in G1 vaccinated with Nt low dose, one animal out of $15(6.7 \%)$ cattle showed cutaneous nodules localized in both sides of the neck measuring $0.5-1 \mathrm{~cm}$, from day $14 \mathrm{pv}$. In $\mathrm{G} 2$, one animal showed lesions in the neck of the same size from day $14 \mathrm{pv}$, and another showed head and neck nodules of $1-2 \mathrm{~cm}$ of diameter from D13 pv (6.7\%). In two animals of $\mathrm{G} 2$, local inflammation reactions of $3 \times 3 \mathrm{~cm}$ in diameter were detected at the inoculation sites, starting between days 7 and $9 \mathrm{pv}$ (Table 4). 


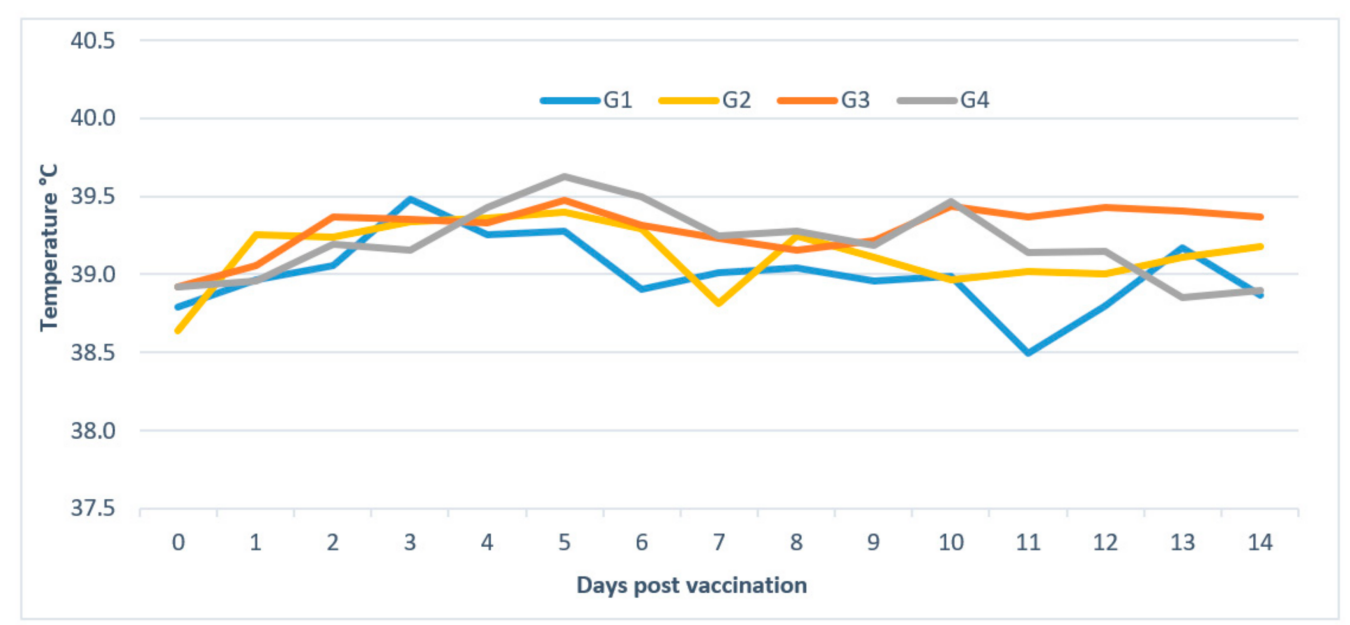

Figure 3. Average temperature of animals of G1 vaccinated with low dose of Neethling strain, G2 vaccinated with high dose of Neethling strain, G3 vaccinated with low dose of Kenyan strain, and G4 vaccinated with high dose of Kenya strain.

Table 3. Clinical scoring in animals vaccinated with Neethling $t$ and Kenyan strains at different doses.

\begin{tabular}{|c|c|c|c|c|c|}
\hline \multirow{2}{*}{$\begin{array}{c}\text { Group } \\
\text { Vaccine }\end{array}$} & G1 & G2 & G3 & G4 & \multirow{2}{*}{$\begin{array}{c}\text { G5 } \\
\text { Unvaccinated }\end{array}$} \\
\hline & \multicolumn{2}{|c|}{ Neethling Strain } & \multicolumn{2}{|c|}{ Kenyan Strain } & \\
\hline Dose & Low & High & Low & High & - \\
\hline Number of animals & 15 & 30 & 12 & 12 & 4 \\
\hline Fever (days/animal) & 0.93 & 1.87 & 2.33 & 2.92 & 0 \\
\hline Duration of fever in days & 2 & 4.3 & 5.6 & 3.8 & 0 \\
\hline $\begin{array}{l}\text { Number of animals showing local } \\
\text { reaction at the inoculations site }\end{array}$ & 0 & 2 & 0 & 1 & 0 \\
\hline Clinical score & 1 & 1 & 1 & 2.5 & 0 \\
\hline $\begin{array}{l}\text { Number of cases } \\
\text { Percentage }\end{array}$ & $\begin{array}{c}1 \\
6.7 \%\end{array}$ & $\begin{array}{c}2 \\
6.7 \%\end{array}$ & $\begin{array}{c}0 \\
0 \%\end{array}$ & $\begin{array}{c}3 \\
25.0 \%\end{array}$ & $\begin{array}{c}0 \\
0 \%\end{array}$ \\
\hline
\end{tabular}

Table 4. A total cumulative scoring of animals presenting LSD-like disease.

\begin{tabular}{cccccc}
\hline Group & Animal ID & Fever & Local Inflammation & Neethling Disease & Total Score \\
\hline G1 & 833 & 1 & 0 & 1 & 2 \\
\hline \multirow{2}{*}{ G2 } & 906 & 1 & 2 & 2 & 5 \\
& 4599 & 1 & 2 & 2 & 5 \\
\hline G3 & All & 1 & 0 & 0 & 1 \\
\hline \multirow{3}{*}{ G4 } & 661 & 2 & 0 & 5 & 7 \\
& 5136 & 1 & 0 & 3 & 4 \\
\hline
\end{tabular}

In G4, which comprised a total of 12 cattle vaccinated with LSD Kn high dose, the percentage of animals showing generalized skin lesions after vaccination was as high as $25 \%$. One animal displayed generalized nodules across the whole body, starting from D13 pv. The second animal showed skin nodules of $0.5 \times 2 \mathrm{~cm}$ in diameter which appeared 21 days pv in the neck, posterior parts of the body, and perineum (Figure 4). In the third calf, small lesions $0.5-1 \mathrm{~cm}$ in diameter were noted on day $7 \mathrm{pv}$ in the head and perineal area; on day $14 \mathrm{pv}$, skin lesions become more accentuated in the head and thigh regions with nodules detectable by palpation in the neck and chest. A local reaction of $2-3 \mathrm{~cm}$ in diameter was also observed at the inoculation site in this animal. 
(a)
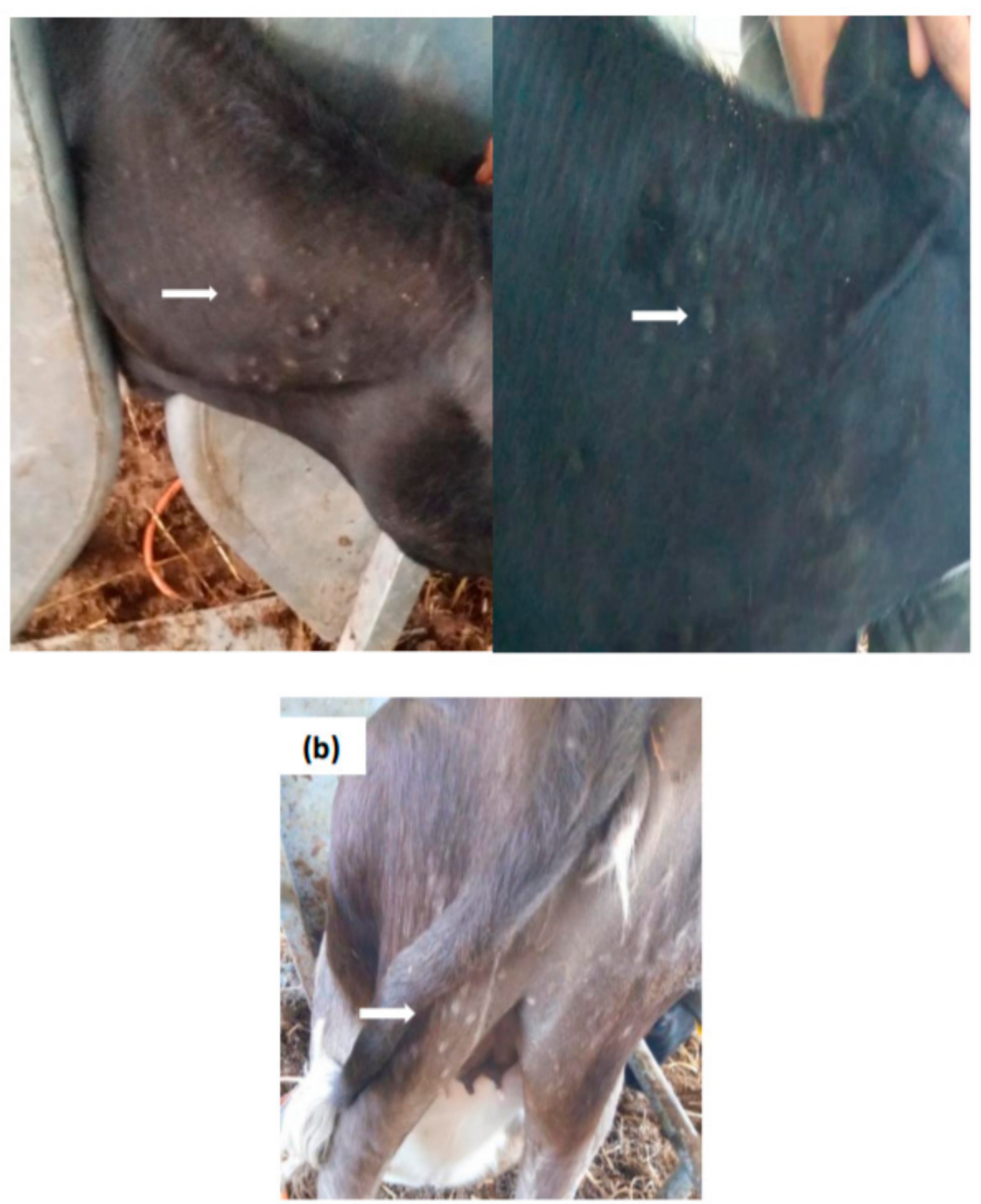

Figure 4. (a) Localized skin lesions in the neck seen in cattle vaccinated with Neethling strain (G2). (b) Localized skin lesions in thighs regions and perineum seen in cattle vaccinated with Kenya strain (G4). Arrows show skin lesions.

Observed nodules in these animals were located on various parts of the body but mainly on the head and neck. The skin lesions looked like LSD nodules but were smaller and led to crusts before healing. Animals stayed healthy, with good bodily condition with no other clinical signs observed. The cutaneous lesions disappeared in 3 weeks and all affected cattle healed in about 1 month.

Absence of skin lesions in unvaccinated animals of G5 confirmed the non-diffusion of the vaccine strain under Biosafety Level 3 (BSL3) conditions in a controlled environment.

Seroconversion: Animals vaccinated with LSD Nt at low dose (G1) showed seroconversion starting on day $14 \mathrm{pv}(20 \%)$ and reached $47 \%$ by day $42 \mathrm{pv}$. Those cattle vaccinated with the LSD Nt high dose (G2) showed a positive antibody response starting on day $7 \mathrm{pv}$ and reached a percentage of $73 \%$ on day $35 \mathrm{pv}$. Regarding the LSD Kn vaccine at low dose (G3), animals seroconverted from day $14 \mathrm{pv}$ and reached $100 \%$ on day $21 \mathrm{pv}$. For cattle vaccinated with high dose (G4), $25 \%$ seroconverted already on day $7 \mathrm{pv}$ and all of the animals were seropositive by day $21 \mathrm{pv}$ (Table 5). All animals remained positive for more than 3 months. The average neutralizing antibody titers recorded on D28 post vaccination was 1.2 at low dose (G1) and 1.7 at high dose (G2) for Nt strain and 1.6 at low dose (G3) and 2.1 at high dose (G4) for Kn strain. 
Table 5. Percentage of positive animals by VNT.

\begin{tabular}{ccccccccccc}
\hline Vaccine & \multicolumn{7}{c}{ A Total Number of Seropositive Animals/Day Post Vaccination } \\
\hline Group & Number of Animals & D0 & D7 & D14 & D21 & D28 & D35 & D42 & D60 & D90 \\
\hline Nt low dose (G1) & 15 & 0 & 0 & 3 & 6 & 6 & 6 & 7 & 7 & 6 \\
Nt high dose (G2) & 30 & 0 & 5 & 8 & 15 & 20 & 22 & 22 & 22 & 14 \\
Kn low dose (G3) & 12 & 0 & 0 & 8 & 12 & 12 & 12 & 12 & 12 & 9 \\
Kn high dose (G4) & 12 & 0 & 3 & 10 & 12 & 12 & 12 & 12 & 12 & 12 \\
Unvaccinated (G5) & 5 & 0 & 0 & 0 & 0 & 0 & 0 & 0 & 0 & 0 \\
\hline
\end{tabular}

Absence of seroconversion in animals of G5 confirmed the non-diffusion of the vaccine strain.

\subsection{Viral Excretion}

No viral DNA was detected in oral or nasal swabs collected from cattle vaccinated with $\mathrm{Nt}$ and Kn strains, except in samples collected from those six animals that showed a Neethling-like disease after vaccination. In cattle showing severe vaccine side-effects, the virus was detected in oral and nasal swabs first on day $9 \mathrm{pv}$, and they remained PCR-positive until day $28 \mathrm{pv}$, with a cycle threshold $\left(\mathrm{C}_{\mathrm{t}}\right)$ value ranging between 26.7 and 36.0. On day $35 \mathrm{pv}$, all six animals tested negative again. Skin crusts taken from animals showing skin lesions tested qPCR-positive with the $C_{t}$ varying between 19.1 and 36.0 on day 23 pv. Virus isolation was attempted from a sample collected 23 days pv and showed characteristic CPE on cells, indicating that the virus was live. However, for this sample, no sequencing of the DNA of the isolated virus was carried out.

All unvaccinated animals remained clinically healthy and PCR-negative throughout the trial.

\subsection{Statistical Analysis}

The Neethling-like disease parameter was significantly higher $(p \leq 0.05)$ in G4 of cattle vaccinated with LSD Kn vaccine at high dose (25\%) compared to cattle vaccinated at low dose $(0 \%)$. Clinical scores were significantly higher $(p \leq 0.05)$ in animals vaccinated with LSD Kn strain compared to animals vaccinated with LSD Nt strain. Subject to the unequal number of animals in each group, the average clinical score for cattle vaccinated with $\mathrm{Kn}$ vaccine was 1.75, whereas the clinical score was 1 in cattle vaccinated with LSD Nt vaccine.

\section{Discussion}

Lumpy skin disease outbreaks cause substantial financial losses for farmers and the whole cattle farming industry in endemic and newly affected regions [1]. The most effective tool to limit spread of the vector-borne LSDV is to carry out large-scale vaccination campaigns, comprising the whole cattle population together with cattle movement restrictions. Live attenuated LSDV vaccines are known to provide a good protection in cattle [35].

Vaccination with the LSD Nt strain, using a high vaccination coverage allows an efficient control of the spread of the disease [36]. Heterologous vaccines based on sheeppox strain have been used for cattle against LSDV in some countries [37]. Protection by sheeppox RM-65 strain at 10 times dose of small ruminants has been reported to be partial for LSD [16,21,38-40]. Goatpox virus vaccines have been shown experimentally to be effective against LSD $[7,41]$, but more data on the efficacy of these vaccine in the field need to be obtained.

The most common vaccine used against LSDV worldwide is the South African " $\mathrm{Nt}^{\prime}$ strain [12,42]; as such, more animals were included in groups vaccinated with the Nt strain (G1 and G2) than in the Kn vaccine groups (G3 and G4). The number of experimental animals allowed the detection of LSD-like disease and comparison between $\mathrm{Nt}$ and $\mathrm{Kn}$ strains, as well as high and low vaccine doses. 
Live Nt strain-based vaccines have been associated with adverse vaccine reactions, raising concerns on the safety of vaccination $[18,22,43,44]$. In addition, no post-vaccination safety data are available for $\mathrm{Kn}$ strain in cattle, as this vaccine has been mainly used in small ruminants to prevent sheeppox and goatpox. Very few studies have reported vaccination of cattle with Kn SGP O-240 or O-180 strains against LSD [7,15,16].

The aim of the study was to investigate the etiology of the post-vaccination reactions observed in cattle. The most commonly noted side-effect is a small local reaction at the vaccination site, caused by local replication of the vaccine virus, which can also be considered as an indication of protection [45]. Some animals may show generalized LSDlike nodules which, in most cases, can be differentiated from those caused by the virulent LSD field strains, as they are smaller and disappear within 1-3 weeks [24,43]. Currently, there is no consensus on the proportion of animals showing vaccine side-effects and the real consequences of vaccination, considering cattle production, such as effect of vaccination on the milk yield.

In this study carried out in a controlled environment, the clinical reaction of naïve healthy calves after vaccination with $\mathrm{Nt}$ and $\mathrm{Kn}$ vaccines at two different dosage levels was investigated, namely, $10^{4.0}$ (low) and $10^{5.0} \mathrm{TCID}_{50}$ (high). To our knowledge, this is the first study of this phenomenon, using a sufficient number of animals in a high containment facility. Within all groups, six experimental animals out of $69(8.7 \%)$ showed a "Neethling disease" vaccine reaction, and only one of them, vaccinated using the high dose of Kn vaccine (G4), presented a generalized and severe post-vaccination reaction. The study demonstrated that, for LSD Nt and Kn vaccines, the appearance of vaccine induced LSD-like disease was not strictly related to a particular strain, as reaction was observed after vaccination with both strains. However, the percentage of LSD-like disease was higher in those groups (G4) vaccinated with the Kn strain. Cattle vaccinated with $\mathrm{Nt}$ strain showed three LSD-like cases among 45 animals (6.7\%), while cattle vaccinated with the Kn strain revealed three cases among 24 (12.5\%). Regarding vaccine dose, 3.7\% of the animals presented LSD-like disease at the low dose, while $11.9 \%$ showed skin lesions when vaccinated with the high vaccine dose, proving a clear dose-effect relationship, more visible with the Kn strain $(25 \%)$ at a high dose versus none at the low dose. The size and the localization of LSD-like nodules were also more accentuated in calves vaccinated with the high vaccine doses. These results are compatible with a study that showed the presence of systemic vaccine adverse reactions only in cattle that received the high dosage of sheeppox RM65 vaccine [20]. All confirmed cases of Neethling disease appeared within a period of 7-17 days from vaccination, and animals recovered within 11-17 days.

However, nasal and saliva swabs and skin lesions collected from vaccinated animals showing LSD-like disease tested LSD-positive by PCR. However, further well-designed investigations on potential transmission of the vaccine virus to cohabitant animals under field conditions are required. In a study by Bedekovic and coworkers, the level of vaccine virus was higher in the skin lesions, which may affect spread via mechanical transmission by insects or ticks feeding on skin lesions [43]. Interestingly, in a Croatian study, when the vaccine virus was isolated and sequenced from the skin lesions of the vaccinated animals, the obtained data showed that the virus remained fully attenuated [46].

LSD-like skin lesions are often detected in vaccinated animals after vaccination campaigns in newly affected countries [23]. The high-production dairy cows seem to be most susceptible to the natural disease $[47,48]$, and the same could be to be the case for the vaccine virus. Severe vaccine side-effects may hamper the eradication of LSD because of the concerns of transmission of the live vaccine virus, recombination of the vaccine with field strains, and unwillingness of farmers to use the vaccine. Previously, too low attenuation level of the vaccine strain, use of high vaccine dosage, or factors related to recurrent infections in vaccinated animals have been suggested to be the reason for the appearance of the vaccine side-effects [38]. In this study, the host-dependent factors could not be considered, because only calves in good health and condition were used. However, the Kn strain presented more "Neethling disease" cases, with a percentage of $25 \%$ at high 
dose (3/12), compared to $6.7 \%(2 / 30)$ with the Nt strain at the same dose. Moreover, a long duration of fever reaction was recorded, even when the $\mathrm{Kn}$ strain was used at a low dose. In previous studies, it was suggested that the low-level attenuation of KSGP O-240 vaccine is likely to be not sufficient for the safe use of this vaccine in cattle, causing clinical disease in vaccinated animals [38]. The Kn strain used in this study was refreshed by carrying out an additional passage in experimental calves to increase its replication capacity.

One of the parameters that correlates with the protection provided by the vaccine against LSDV is the humoral response in vaccinated animals. However, the absence of antibodies does not necessarily mean the absence of protection, because the cell-mediated immunity plays a dominant role in capripox infections [49]. Some animals may remain seronegative after natural infection or vaccination, even though they would be fully protected against the disease [14,45]. In this experiment, animals in group G2 that received the high dose of LSD Nt strain vaccine showed a better humoral response than those that received the low dose. Kn vaccines induced a better antibody response than $\mathrm{Nt}$ vaccines. In another study, a significant increase of capripoxvirus-specific antibody titers was seen from day 21 up to day 42 after vaccination, and antibodies remained detectable for about 7 months [50]. Hamdi and coworkers reported that the live vaccine induced an antibody response reaching $50 \%$ on day $28 \mathrm{pv}$ [51].

In the study by Milovanović and coworkers, LSD-specific antibodies were detected with VNT for 46 to 47 weeks after vaccination in 35\% of vaccinated cattle with the LSDV Nt vaccine (Onderstepoort Biological Products, OBP, Pretoria, South Africa) [50]. In another study, antibodies against LSDV were detected by VNT in 34\% of samples for 20 days after vaccination using the OBP Lumpy Skin Disease vaccine (Onderstepoort Biological Products) [52]. However, in an Ethiopian study, vaccination of cattle with KSGP O-180 and $\mathrm{Nt}$ strains did not elicit a detectable antibody response using the indirect fluorescence antibody test (IFAT). All experimental animals vaccinated with the Gorgan goatpox strain were fully protected against a challenge with a highly virulent LSD field strain, although only $50 \%$ of them tested seropositive using the IFAT [7]. Absence of seroconversion in cattle vaccinated with $\mathrm{Nt}$ and KSGP O-180 strains was associated with poor immunogenicity of these locally produced vaccines, likely to be due to over-attenuation or some other failure in these vaccine products [7]. In the present study, the original Kn LSD strain was passaged 3-4 times at the Pirbright Institute, and one additional passage in cattle was carried out during this study. This is a very low passage number for the homologous vaccine against LSDV. Interestingly, during the refreshment passage prior to the preparation of the vaccine, the Kn strain caused a local reaction at the vaccination site only in one out of five inoculated calves. This finding can be explained by the low number of cattle used in the refreshment trial and is in agreement with the earlier observations on the appearance of clinical signs in experimental animals [5,7]. All animals vaccinated with the Kn strain (24/24) seroconverted, but a higher dosage of the Kn vaccine was less safe as $25 \%$ of vaccinated cattle showed LSD-like skin nodules after vaccination. Seroconversion was detected in all experimental animals vaccinated with the $\mathrm{Nt}$ strain.

A comparison of the sequence alignment of the GPCR and RPO30 genes showed that the Kn strain used in this study clustered at the nucleotide level with Kn vaccine strain LSDV KSGP O-240 and with recently analyzed LSDV Bangladesh isolates [53] A comparison of full genome sequences with KX683219 indicated the highest percentage sequence identity to the vaccine strain $(99 \%)$.

The existence of vaccine-like field isolates with mixed characteristics between common field viruses and the vaccine used against LSD has been reported by Russian scientists [54]. More recently, a field LSDV isolated from Kurgan, Russia, exhibited similarities to LSDV KSGP O-240 and LSDV NI2490, according to an analysis of GPCR and RPO30 gene fragments [55]. The comparison of the GPCR gene indicated that the Kn strain used in our study is identical to the other KSGP O-240 strain and those LSDV strains currently circulating in Bangladesh [48]. Previously, it was suggested that KSGP O-240 strain vaccines are known to cause side-effects in cattle if used in naïve animals due to insufficient attenuation [38]. 
The similarity of the Kn strain of this study with already published sequences of KSGP O-240 and KS-1 strains provides further evidence that KSGP strains are not sufficiently attenuated in vaccines, causing clinical signs in previously unvaccinated naïve animals and, to confirm this statement, additional protection data and transmission studies would be important. If the strain is under-attenuated for cattle, it cannot be excluded that KSGP O-240 or O-180 strains may spread from vaccinated to unvaccinated naïve animals in the field setting.

It also needs to be considered that in real life, some vaccinated animals may already be incubating the virulent field strain when vaccinated. In this case, if the used vaccine is not sufficiently attenuated, it may result in a recombination of the genomes of the two viruses, i.e., the vaccine and the field virus, after entry into the same cell.

\section{Conclusions}

Results of this experiment highlight constraints related to the use of live vaccines, especially to protect against LSD. Under controlled conditions, groups of naïve healthy calves were vaccinated with two LSD vaccines based on Nt and Kn strains, at two different doses. Cases showing LSD-like lesions were observed among 69 vaccinated animals $(8.7 \%)$. Lesions were observed more frequently when a high vaccine dose $(12 \%)$ was used compared to the normal dose (37\%). The percentage was higher in the Kn strain. Vaccination induced satisfactory seroconversion, confirming that the $\mathrm{Nt}$ strain can be used for mass vaccination to protect cattle against LSD. However, precaution should be taken not to use a high vaccine dose, which is likely to cause adverse reactions in vaccinated animals.

Author Contributions: Data curation, Z.B., J.H., S.F., S.K. and M.J.; formal analysis, E.T. and M.E.; investigation, Z.B.; methodology, M.E.; project administration, Z.B.; resources, K.O.T.; supervision, K.O.T. and M.E.; validation, O.F.F. and E.T.; writing—original draft, Z.B. All authors have read and agreed to the published version of the manuscript.

Funding: This research received no external funding.

Institutional Review Board Statement: Before commencing this study, animal experiments were carried out in accordance with the international guidelines for care and handling of experimental animals. The study protocol was submitted and approved by the Internal Ethic Committee "The Internal Ethic Committee for Animal Experiments, MCI Santé Animale". The internal ethical committee of MCI analyzed and approved the protocol before starting the trial. Consent was obtained from the MCI Santé Animale breeding farm to use the animals in the study.

Informed Consent Statement: Not applicable.

Data Availability Statement: The datasets used and/or analyzed during the current study are available from the corresponding author on reasonable request. All recorded raw data are archived in MCI Santé Animale.

Acknowledgments: All authors read and approved the content of this manuscript and contributed significantly to the work. The authors gratefully acknowledge the support for this study from MCI (Multi-Chemical Industry) Santé Animale.

Conflicts of Interest: The authors declare no conflict of interest.

\section{References}

1. FAO. Introduction and Spread of Lumpy Skin Disease in South, East and Southeast Asia-Qualitative Risk Assessment and Management; FAO: Rome, Italy, 2020.

2. Buller, R.; Arif, B.; Black, D.; Dumbell, K.; Esposito, J.; Lefkowitz, E.J.; McFadden, G.; Moss, B.; Mercer, A.; Moyer, R.; et al. Family Poxviridae; Elsevier Academic Press: San Diego, CA, USA, 2005; pp. 117-133.

3. Chihota, C.M.; Rennie, L.F.; Kitching, R.P.; Mellor, P.S. Mechanical transmission of lumpy skin disease virus by Aedes aegypti (Diptera: Culicidae). Epidemiol. Infect. 2001, 126, 317-321. [CrossRef] [PubMed]

4. Tuppurainen, E.S.; Stoltsz, W.H.; Troskie, M.; Wallace, D.B.; Oura, C.A.L.; Mellor, P.S.; Coetzer, J.A.W.; Venter, E.H. A potential role for ixodid (hard) tick vectors in the transmission of lumpy skin disease virus in cattle. Transbound. Emerg. Dis. 2011, 58, 93-104. [CrossRef] [PubMed] 
5. Carn, M.; Kitching, P. An investigation of possible routes of transmission of lumpy skin disease virus (Neethling). Epidemiol. Infect. 1995, 114, 219-226. [CrossRef] [PubMed]

6. Bowden, T.; Babiuk, S.; Parkyn, G.; Copps, J.; Boyle, D.B. Capripoxvirus tissue tropism and shedding: A quantitative study in experimentally infected sheep and goats. Virology 2008, 371, 380-393. [CrossRef]

7. Gari, G.; Abie, G.; Gizaw, D.; Wubete, A.; Kidane, M.; Asgedom, H.; Bayissa, B.; Ayelet, G.A.L.; Oura, C.; Roger, F.; et al. Evaluation of the safety, immunogenicity and efficacy of three capripoxvirus vaccine strains against lumpy skin disease virus. Vaccine 2015, 33, 3256-3261. [CrossRef]

8. Lubinga, J.C.; Tuppurainen, E.S.M.; Mahlare, R.; Coetzer, J.A.W.; Stoltsz, W.H.; Venter, E.H. Evidence of transstadial and mechanical transmission of lumpy skin disease virus by Amblyomma hebraeum ticks. Transbound. Emerg. Dis. 2015, 62, 174-182. [CrossRef]

9. Sohier, C.; Haegeman, A.; Mostin, L.; De Leeuw, I.; Van Campe, W.; De Vleeschauwer, A.; Tuppurainen, E.S.; van den Berg, T.; De Regge, N.; De Clercq, K. Experimental evidence of mechanical lumpy skin disease virus transmission by Stomoxys calcitrans biting flies and Haematopota spp. Horseflies. Sci. Rep. 2019, 9, 1-10. [CrossRef]

10. Davies, F. Lumpyskin Disease; Cambridge University Press: London, UK, 1981.

11. Prozesky, L.; Barnard, B. A study of the pathology of lumpy skin disease in cattle. Onderstepoort J. Vet. Res. 1982, 49, 167-175.

12. Davies, F. Lumpy skin disease, an african capripox virus disease of cattle. Br. Vet. J. 1991, 147, 489-503. [CrossRef]

13. Babiuk, S.; Bowden, T.R.; Parkyn, G.; Dalman, B.; Manning, L.; Neufeld, J. Quantification of Lumpy Skin Disease Virus Following Experimental Infection in Cattle. Transbound. Emerg. Dis. 2008, 55, 299-307. [CrossRef]

14. Weiss, K. Lumpy Skin Disease Virus. Virol. Monogr. 1968, 3, 111-131.

15. Yeruham, I.; Perl, S.; Nyska, A.; Abraham, A.; Davidson, M.; Haymovitch, M.; Zamir, O.; Grinstein, H. Adverse reactions in cattle to a capripox vaccine. Vet. Rec. Rec. 1994, 135, 330-332. [CrossRef]

16. Ayelet, G.; Abate, Y.; Sisay, T.; Nigussie, H.; Gelaye, E.; Jemberie, S.; Asmare, K. Lumpy skin disease: Preliminary vaccine efficacy assessment and overview on outbreak impact in dairy cattle at Debre Zeit, central Ethiopia. Antivir. Res. 2013, 98, 261-265. [CrossRef]

17. Salib, F.A.; Osman, A.H. Incidence of lumpy skin disease among Egyptian cattle in Giza Governorate, Egypt. Vet. World 2011, 4, 162-167. [CrossRef]

18. Tuppurainen, E.; Alexandrov, T.; Beltran-Alcrudo, D. Lumpy Skin Disease Field Manual-A Manual for Veterinarians; FAO Animal Production and Health Manual No.20. Rome; Food and Agriculture Organization of the United Nations (FAO): Rome, Italy, 2017; ISBN 9789251097762.

19. Tuppurainen, E.S.M.; Oura, C.A.L. Review: Lumpy Skin Disease: An Emerging Threat to Europe, the Middle East and Asia. Transbound. Emerg. Dis. 2011, 59, 40-48. [CrossRef]

20. Abutarbush, S.M.; Tuppurainen, E.S. Serological and clinical evaluation of the Yugoslavian RM65 sheep pox strain vaccine use in cattle against lumpy skin disease. Transbound. Emerg. Dis. 2018, 1-7. [CrossRef]

21. Ben-Gera, J.; Klement, E.; Khinich, E.; Stram, Y.; Shpigel, N.Y. Comparison of the efficacy of Neethling lumpy skin disease virus and x10RM65 sheep-pox live attenuated vaccines for the prevention of lumpy skin disease-The results of a randomized controlled field study. Vaccine 2015, 33, 1-6. [CrossRef]

22. Katsoulos, P.D.; Chaintoutis, S.C.; Dovas, C.I.; Polizopoulou, Z.S.; Brellou, G.D.; Agianniotaki, E.I.; Tasioudi, K.E.; Chondrokouki, E.; Papadopoulos, O.; Karatzias, H.; et al. Investigation on the incidence of adverse reactions, viraemia and haematological changes following field immunization of cattle using a live attenuated vaccine against lumpy skin disease. Transbound. Emerg. Dis. 2018, 65, 174-185. [CrossRef]

23. Calistri, P.; Declercq, K.; Gubbins, S.; Klement, E.; Stegeman, A.; Cortinas Abrahantes, J.; Sotiria-Eleni, A.; Broglia, A.; Gogin, A. Lumpy skin disease III. Data collection and analysis. EFSA J. 2019, 17, 1-26. [CrossRef]

24. Abutarbush, S.M.; Hananeh, W.M.; Ramadan, W.; Al Sheyab, O.M.; Alnajjar, A.R.; Al Zoubi, I.G.; Knowles, N.; BachanekBankowska, K.; Tuppurainen, E.S. Adverse Reactions to Field Vaccination Against Lumpy Skin Disease in Jordan. Transbound. Emerg. Dis. 2017, 63, e213-e219. [CrossRef]

25. Thompson, J.; Higgins, D.; Gibson, T. CLUSTAL W: Improving the sensitivity of progressive multiple sequence alignment through sequence weighting, position-specific gap penalties and weight matrix choice. Nucleic Acids Res. 1994, 22, 4673-4680. [CrossRef]

26. Hall, T. BioEdit: A User-Friendly Biological Sequence Alignment Editor and Analysis for Windows 95/98/NT: Nucleic Acids Symp; Series 41; Oxford University Press: Oxford, UK, 1999; pp. 95-98.

27. Tamura, K.; Peterson, D.; Peterson, N.; Stecher, G.; Nei, M.; Kumar, S. MEGA5: Molecular evolutionary genetics analysis using maximum likelihood, evolutionary distance, and maximum parsimony methods. Mol. Biol. Evol. 2011, 28, 2731-2739. [CrossRef]

28. Saitou, N.; Nei, M. The neighbor-joining method: A new method for reconstructing phylogenetic trees. Mol. Biol. Evol. 1987, 4, 406-425.

29. Felsenstein, J. Confidence limits on phylogenies: An approach using the bootstrap. Evolution 1985, 39, 783-791. [CrossRef] [PubMed]

30. Kimura, M. A Simple Method for Estimating Evolutionary Rate of Base Substitutions through Comparative Studies of Nucleotide Sequences. J. Mol. Evol. 1980, 16, 111-120. [CrossRef]

31. Vandenbussche, F.; Mathijs, E.; Haegeman, A.; Al-Majali, A.; Van Borm, S.; De Clercqb, K. Complete Genome Sequence of Capripoxvirus Strain KSGP 0240 from a Commercial Live Attenuated Vaccine. Genome Announc. 2016, 4, e01114-16. [CrossRef] 
32. Parlement Européen et du Conseil de l’Union Européenne. Directives EU Commission Protection des animaux utilisés à des fins scientifiques. J. Off. l'Union Eur. 2010, 276, 1-162.

33. OIE. Terrestrial Animal Health Code Use of Animals. In Research and Education; Chapter 7.8; OIE Terrestrial Animal Health Code; OIE: Paris, France, 2016; pp. 1-10.

34. Office International des Epizooties. Manual of diagnostic tests and vaccines for terrestrial animals. In Chapter 2.4.13. Paris: Lumpy Skin Disease; OIE: Paris, France, 2017; pp. 1-14.

35. Tuppurainen, E.S.; Venter, E.; Shisler, J.; Gari, G.; Mekonnen, G.; Juleff, N.; Lyons, N.; De Clercq, K.; Upton, C.; Bowden, T.; et al. Review: Capripoxvirus Diseases: Current Status andOpportunities for Control. Transbound. Emerg. Dis. 2017, 64, 729-745. [CrossRef]

36. EFSA (European Food Safety Authority); Calistri, P.; De Clercq, K.; Gubbins, S.; Klement, E.; Stegeman, A.; Cortiñas Abrahantes, J.; Marojevic, D.; Antoniou, S.E.; Broglia, A. Lumpy Skin Disease Epidemiological Report IV: Data Collection and Analysis. EFSA J. 2020, 18, e06010.

37. Kitching, R. Vaccines for lumpy skin disease, sheep pox and goat pox. Dev. Biol. 2003, 114, 161-167.

38. Tuppurainen, E.S.; Pearson, C.R.; Bachanek-bankowska, K.; Knowles, N.J.; Amareen, S.; Frost, L.; Henstock, M.R.; Lamien, C.E.; Diallo, A.; Mertens, P.P.C. Characterization of sheep pox virus vaccine for cattle against lumpy skin disease virus. Antivir. Res. 2014, 109, 1-6. [CrossRef] [PubMed]

39. Brenner, J.; Bellaiche, M.; Gross, E.; Elad, D.; Oved, Z.; Haimovitz, M.; Wasserman, A.; Friedgut, O.; Stram, Y.; Bumbarov, V.; et al. Appearance of skin lesions in cattle populations vaccinated against lumpy skin disease: Statutory challenge. Vaccine 2009, 27, 1500-1503. [CrossRef] [PubMed]

40. Kumar, S.M. An Outbreak of Lumpy Skin Disease in a Holstein Dairy Herd in Oman: A Clinical Report. Asian J. Anim. Vet. Adv. 2011, 6, 851-859. [CrossRef]

41. Zhugunissova, K.; Bulatov, Y.; Orynbayev, M.; Kutumbetov, L.; Abduraimov, Y.; Shayakhmetova, Y.; Taranov, D.; Amanova, Z.; Mambetaliyev, M.; Absatova, Z.; et al. Goatpox virus (G20-LKV) vaccine strain elicits a protective response in cattle against lumpy skin disease at challenge with lumpy skin disease virulent field strain in a comparative study. Vet. Microbiol. 2020, $245,108695$. [CrossRef]

42. Klement, E.; Broglia, A.; Sotiria Eleni, A.; Tsiamadis, V.; Plevraki, E.; Petrović, T.; Polaček, V.; Debeljak, Z.; Miteva, A.; Tsviatko, A.; et al. Neethling vaccine proved highly effective in controlling lumpy skin disease epidemics in the Balkans. Prev. Vet. Med. 2018. [CrossRef]

43. Bedekovic, T.; Simic, I.; Kresic, N.; Lojkic, I. Detection of lumpy skin disease virus in skin lesions, blood, nasal swabs and milk following preventive vaccination. Transbound. Emerg. Dis. 2017, 1-6. [CrossRef]

44. Gelaye, E.; Belay, A.; Ayelet, G.; Jenberie, S.; Yami, M.; Loitsch, A.; Tuppurainen, E.; Grabherr, R.; Diallo, A.; Lamien Euloge, C. Capripox disease in Ethiopia: Genetic differences between field isolates and vaccine strain, and implications for vaccination failure. Antivir. Res. 2015, 119, 28-35. [CrossRef]

45. Tuppurainen, E.S.M.; Antoniou, S.; Tsiamadis, E.; Topkaridou, M.; Labus, T.; Debeljak, Z.; Plavšić, B.; Miteva, A.; Alexandrov, T.; Pite, L.; et al. Field observations and experiences gained from the implementation of control measures against lumpy skin disease in South-East Europe between 2015 and 2017. Prev. Vet. Med. 2018, 1-39. [CrossRef]

46. Lojkić, I.; Šimić, I.; Krešić, N.; Bedeković, T. Complete genome sequence of a lumpy skin disease virus strain isolated from the skin of a vaccinated animal. Genome Announc. 2018, 6, e00482-18. [CrossRef]

47. Şevik, M.; Doğan, M. Epidemiological and Molecular Studies on Lumpy Skin Disease Outbreaks in Turkey during $2014-2015$. Transbound. Emerg. Dis. 2016, 64, 1268-1279. [CrossRef]

48. Tageldin, M.H.; Wallace, D.B.; Gerdes, G.H.; Putterill, J.F.; Greyling, R.R.; Phosiwa, M.N.; Al Busaidy, R.M.; Al Ismaaily, S.I. Lumpy skin disease of cattle: An emerging problem in the Sultanate of Oman. Trop. Anim. Health Prod. 2014, 46, 241-246. [CrossRef]

49. Norian, R.; Ahangaran, N.; Varshovi, H.; Azadmehr, A. Evaluation of humoral and cell-mediated immunity of two capripoxvirus vaccine strains against lumpy skin disease virus. Iran. J. Virol. 2016, 10, 1-11. [CrossRef]

50. Milovanović, M.; Dietze, K.; Milicévić, V.; Radojičić, S.; Valčić, M.; Moritz, T.; Hoffmann, B. Humoral immune response to repeated lumpy skin disease virus vaccination and performance of serological tests. BMC Vet. Res. 2019, 15, 1-9. [CrossRef]

51. Hamdi, J.; Boumart, Z.; Daouam, S.; El Arkam, A.; Bamouh, Z.; Jazouli, M.; Omari, K.; Fassi, O.; Gavrilov, B.; El Harrak, M. Development and Evaluation of an Inactivated Lumpy Skin Disease Vaccine for Cattle. Vet. Microbiol. 2020, 245, 1-6. [CrossRef]

52. Samojlovic, M.; PolaČek, V.; Gurjanov, V.; LupuloviĆ, D.; LaziĆ, G.; PetroviĆ, T.; LaziĆ, S. Detection of Antibodies Against Lumpy Skin Disease Virus by Virus Neutralization Test and Elisa Methods. Acta Vet. 2019, 69, 47-60. [CrossRef]

53. Badhy, S.C.; Chowdhury, M.G.A.; Settypalli, T.B.K.; Cattoli, G.; Lamien, C.E.; Fakir, M.A.U.; Akter, S.; Osmani, M.G.; Talukdar, F.; Begum, N.; et al. Molecular characterization of lumpy skin disease virus (LSDV) emerged in Bangladesh reveals unique genetic features compared to contemporary field strains. BMC Vet. Res. 2021, 17, 1-11. [CrossRef]

54. Sprygin, A.; Babin, Y.; Pestova, Y.; Kononova, S.; Wallace, D.B.; Van Schalkwyk, A.; Byadovskaya, O.; Diev, V.; Lozovoy, D.; Kononov, A. Analysis and insights into recombination signals in lumpy skin disease virus recovered in the field. PLoS ONE 2018, 12, e0207480. [CrossRef]

55. Kononov, A.; Prutnikov, P.; Bjadovskaya, O.; Kononova, S.; Rusaleev, V.; Pestova, Y.; Sprygin, A. Emergence of a new lumpy skin disease virus variant in Kurgan oblast, Russia, in 2018. Arch. Virol. 2020, 165, 1343-1356. 